\title{
Advances in targeted therapies and new promising targets in esophageal cancer
}

\author{
Abbes Belkhiri', Wael El-Rifai ${ }^{1,2}$ \\ ${ }^{1}$ Department of Surgery, Vanderbilt University Medical Center, Nashville, Tennessee 37232, USA \\ ${ }^{2}$ Department of Veterans Affairs, Tennessee Valley Healthcare System, Nashville, Tennessee 37212, USA \\ Correspondence to: \\ Wael El-Rifai, e-mail: wael.el-rifai@vanderbilt.edu \\ Abbes Belkhiri, e-mail: abbes.belkhiri@vanderbilt.edu \\ Keywords: adenocarcinoma, esophageal, gastric, cancer, targeted therapy \\ Received: September 19, 2014 \\ Accepted: November 15, 2014 \\ Published: January 16, 2015
}

\begin{abstract}
Esophageal cancer, comprising squamous carcinoma and adenocarcinoma, is a leading cause of cancer-related death in the world. Notably, the incidence of esophageal adenocarcinoma has increased at an alarming rate in the Western world. Unfortunately, the standard first-line chemo-radiotherapeutic approaches are toxic and of limited efficacy in the treatment of a significant number of cancer patients. The molecular analysis of cancer cells has uncovered key genetic and epigenetic alterations underlying the development and progression of tumors. These discoveries have paved the way for the emergence of targeted therapy approaches. This review will highlight recent progress in the development of targeted therapies in esophageal cancer. This will include a review of drugs targeting receptor tyrosine kinases and other kinases in esophageal cancer. Additional studies will be required to develop a rational integration of these targeted agents with respect to histologic types of esophageal cancer and the optimal selection of cancer patients who would most likely benefit from targeted therapy. Identification of AURKA and AXL as key molecular players in esophageal tumorigenesis and drug resistance strongly justifies the evaluation of the available drugs against these targets in clinical trials.
\end{abstract}

\section{INTRODUCTION}

The increasing incidence and poor prognosis of esophageal cancer represent a major public health problem worldwide. In 2013, it was estimated that 17,990 new cases of esophageal cancer will be diagnosed and only $15 \%$ of patients will survive their disease in the United States [1]. This malignancy comprises two major histologic types, esophageal squamous cell carcinoma (SCC) and esophageal adenocarcinoma (AC) - together they account for the sixth leading cause of death in the world [2]. Although in the last few decades SCC cases have steadily decreased, the incidence of $\mathrm{AC}$ has increased at an alarming rate ( $>6$-fold) in the Western world [3]. SCC and AC differ substantially in their underlying etiology factors and tumorigenesis. While smoking and alcohol [4], prior head and neck cancer [5], and human papilloma virus infection [6] are risk factors in SCC; gastro-esophageal reflux disease (GERD) and obesity have been associated with increased risk of AC [7].
SCC develops from a premalignant dysplastic lesion that originates from the native squamous epithelium, whereas the development of $\mathrm{AC}$ is initiated from an intestinal metaplastic lesion (Barrett's esophagus, BE) that occurs in response to GERD [8]. In addition to surgical resection, the current standard of care for patients with either SCC or $\mathrm{AC}$ is chemotherapy with cisplatin and 5-fluorouracil (5-FU) [9], and in combination with other agents such as oxaliplatin [10] and irinotecan [11]. Unfortunately, the majority of patients at advanced stages of the disease fail to benefit from these treatments as the 5-year survival rate remains $<15 \%$ [12], underscoring the critical need for more effective therapies. Hence, there is an urgent necessity to identify the underlying molecular alterations of SCC and AC, and characterize molecular signatures to distinguish the two types of esophageal cancer. Genomic, proteomic, and molecular epidemiologic studies have greatly helped identify potential therapeutic targets that could eventually overcome the shortcomings of the current 
standard therapies of esophageal cancer. As part of the International Cancer Genome Consortium project, Song and colleagues [13] conducted a comprehensive genomic analysis of SCC samples and identified several significantly mutated genes, among which ADAM29 and FAM135B. These two genes have not been previously described in SCC. Of note, FAM135B has been characterized as a novel cancer gene that promotes malignancy of SCC cells [13]. A recent similar study on AC samples revealed many new significantly mutated genes including DOCK2 and ELMO1 [14]. Functional analysis indicated that mutations in ELMO1, found in EAC, significantly enhanced cellular invasion; this suggests the potential contribution of RAC1 signaling to Barrett's tumorigenesis [14]. These studies provide a foundation for further investigations to characterize subsets of esophageal cancer that may be clinically useful for developing more effective therapies. Based on the current literature, this review summarizes the targeted therapies in clinical development and proposes potential novel therapeutic targets in esophageal SCC and $\mathrm{AC}$.

\section{Targeted therapies for esophageal cancer in development}

During the past two decades, the emerging understanding of the underlying molecular mechanisms of carcinogenesis that helped identify important molecular targets led to the development of drugs that target specific molecular sites for various types of cancer, including esophageal SCC and AC. These drugs inhibit or interfere with key molecules or signaling pathways that regulate cell growth and proliferation, angiogenesis, apoptosis, invasion and metastasis, and inflammation. Recently, some of these drugs have been clinically tested as monotherapy or in combination with chemotherapy and/or radiotherapy on esophageal and gastro-esophageal junction cancers (Table 1).

\section{Receptor tyrosine kinases}

Receptor tyrosine kinases (RTKs) are the main mediators that transduce extracellular signals into the cell to modulate cellular growth and differentiation. A large body of evidence indicating that the normally tightly controlled and regulated RTKs in normal cells are overexpressed, amplified, and mutated, leading to constitutive activation of RTK signaling, resulting in deregulated cell growth and tumorigenesis (reviewed by [15]). Similarly, gain-of-function mutations of RTK downstream effectors such as RAS, RAF, and PI3K can promote cancer (reviewed by [16]). Our increasing knowledge of the mechanisms of uncontrolled RTK signaling in cancer has provided the rationale for the development of drugs against RTK signaling components (Figure 1).

\section{Epidermal growth factor receptor}

The human epidermal growth factor receptor (EGFR), an HER family member, is a $170-\mathrm{kDa}$ protein with an extracellular ligand-binding domain, a transmembrane domain, and a cytosolic tyrosine kinase domain [17]. Epidermal growth factor and transforming growth factor- $\alpha$ ligands bind and activate the EGFR receptor, followed by internalization of homodimerized or heterodimerized (EGFR binding HER-2 or ERBB3) receptors, leading to autophosphorylation of the intracellular tyrosine kinase domain and activation of several downstream pro-oncogenic signaling pathways [18]. Based on its aberrant activation as a result of gene amplification, overexpression and mutation, and its association with tumorigenesis and poor prognosis; EGFR has been targeted by two classes of drugs: 1) anti-EGFR monoclonal antibodies $(\mathrm{mAb})$ directed at the extracellular domain of the receptor and 2) small molecule EGFR tyrosine kinase inhibitors (TKI). Targeting RGFR with mAbs either as monotherapy or in combination with conventional chemotherapy has proven its first clinical success in patients with advanced colorectal cancer, especially those with wild-type $K R A S[19,20]$. EGFR mutations (5$10 \%$ ) [21], amplification (20-30\%), and overexpression $(30-80 \%)$ in human esophageal SCC and AC have provided the rationale for targeting EGFR in esophageal cancer [22]. This suggests that EGFR amplification and overexpression rather than mutations drive esophageal cancers. Cetuximab, which is a humanized mouse EGFR mAb, has been shown to downregulate EGF-induced EGFR phosphorylation, inhibit homodimerization and heterodimerization of EGFR with HER-2 and downstream signaling in preclinical cell models of gastro-esophageal cancer [23]. In phase II clinical studies, cetuximab in combination with standard chemotherapy regimens significantly improved response rates in patients with gastro-esophageal junction (GEJ) cancer [24] or SCC [25]. However, cetuximab as a single agent has little clinical activity in upper gastrointestinal cancers [26]. A recent randomized phase III clinical study concluded that the combination of cetuximab with capecitabine and cisplatin had no additional clinical advantage to chemotherapy alone in GEJ cancer patients [27]. Nimotuzumab, a humanized EGFR $\mathrm{mAb}$, in combination with standard chemotherapy (cisplatin or 5-fluorouracil) has shown good therapeutic response in patients with SCC [28]. Another EGFR mAb, panitumumab, has been tested in combination with epirubicin, oxaliplatin and capecitabine in metastatic GEJ cancer patients in a randomized phase III clinical trial [29]. The results from this study indicated that addition of panitumumab to the chemotherapy does not increase overall survival.

Several TKIs targeting EGFR have been clinically tested in upper gastrointestinal cancers. In a phase II study, gefitinib in combination with radiotherapy and chemotherapy in patients with advanced esophageal SCC or AC enhanced overall survival [30]. However, in another phase II clinical trial, gefitinib alone has shown 
Table 1: Selected ongoing and recent clinical studies of targeted agents in esophageal and gastro-esophageal junction cancers (ClinicalTrials.gov)

\section{Molecular target Agent \\ Histology (number of enrolled patients) \\ Monotherapy (NCT identifier, clinical trial phase)}

Agent + chemotherapy

and/or radiotherapy

(NCT identifier, clinical

trial phase)

\begin{tabular}{|c|c|c|c|c|}
\hline EGFR & Nimotuzumab & SCC (20) & NCT02011594, P2 & \\
\hline & & $\operatorname{SCC}(9,144)$ & NCT01993784, P1/2 & NCT01232374, P2 \\
\hline & & SCC/AC (104) & & NCT01249352, P2/3 \\
\hline & Panitumumab & SSC (300) & & NCT01627379, P3 \\
\hline & & SSC/AC (36) & & NCT01128387, P1/2 \\
\hline & & AC/GEJ (574) & & NCT00824785, P3 \\
\hline & Cetuximab & GEJ (904) & & NCT00678535, P3 \\
\hline & Icotinib & $\operatorname{SCC}(50)$ & NCT01973725, P2 & \\
\hline & Gefitinib & AC/GEJ (72) & NCT00100945, P2 & \\
\hline & & $\mathrm{SCC} / \mathrm{AC}(70)$ & & NCT01291823, P2 \\
\hline & & SCC/AC/GEJ (80) & & NCT00258323, P2 \\
\hline \multirow[t]{2}{*}{ VEGFR-2 } & Ramucirumab & AC/GEJ (162) & & NCT01246960, P2 \\
\hline & & GEJ (665) & & NCT01170663, P3 \\
\hline HER-2 & $\begin{array}{l}\text { Pertuzumab/ } \\
\text { Trastuzumab }\end{array}$ & GEJ (780) & & NCT01774786, P3 \\
\hline \multirow[t]{3}{*}{ EGFR/HER-2 } & Lapatinib & SCC (24) & NCT01666431, P2 & \\
\hline & & GEJ (28) & & NCT00313599, P1 \\
\hline & & AC/GEJ (13) & & NCT01395537, P1/2 \\
\hline HER-2 & Afatinib & GEJ (40) & NCT01522768, P2 & \\
\hline \multirow[t]{2}{*}{ c-MET } & Onartuzumab & GEJ (564) & & NCT01662869, P3 \\
\hline & Rilotumumab & GEJ (450) & & NCT02137343, P3 \\
\hline \multirow[t]{3}{*}{ RTKs } & Sunitinib & GEJ (98) & & NCT00891878, P2 \\
\hline & & GEJ (30) & & NCT00524186, P1 \\
\hline & Sorafenib & SCC/AC/GEJ (35) & NCT00917462, P2 & \\
\hline $\mathrm{Src} / \mathrm{Abl}$ & Saracatinib & GEJ (21) & NCT00607594, P2 & \\
\hline AURKA & MLN8237 & GEJ (273) & NCT01045421, P1/2 & \\
\hline AKT & MK2206 & GEJ (75) & NCT01260701, P2 & \\
\hline PI3K & BKM-120 & $\operatorname{SCC}(41)$ & NCT01806649, P2 & \\
\hline \multirow[t]{3}{*}{ mTOR } & RAD001 & SCC/AC (50) & NCT00985192, P2 & \\
\hline & & AC/GEJ (44) & & NCT01231399, P1/2 \\
\hline & & SCC/AC (52) & & NCT01490749, P1 \\
\hline Proteasome & Bortezomib & GEJ (58) & & NCT00061932, P2 \\
\hline
\end{tabular}

Abl, Abelson murine leukemia; AC, esophageal adenocarcinoma; AURKA, aurora kinase A; EGFR, epidermal growth factor receptor; GEJ, gastro-esophageal junction adenocarcinoma; HER-2, human epidermal growth factor receptor; mTOR, mammalian target of rapamycin; PI3K, phosphoinositide 3-kinase; RTKs, receptor tyrosine kinases; SCC, esophageal squamous cell carcinoma; Src, Rous sarcoma virus tyrosine kinase homolog; VEGFR, vascular endothelial growth factor receptor; P, clinical trial phase. 


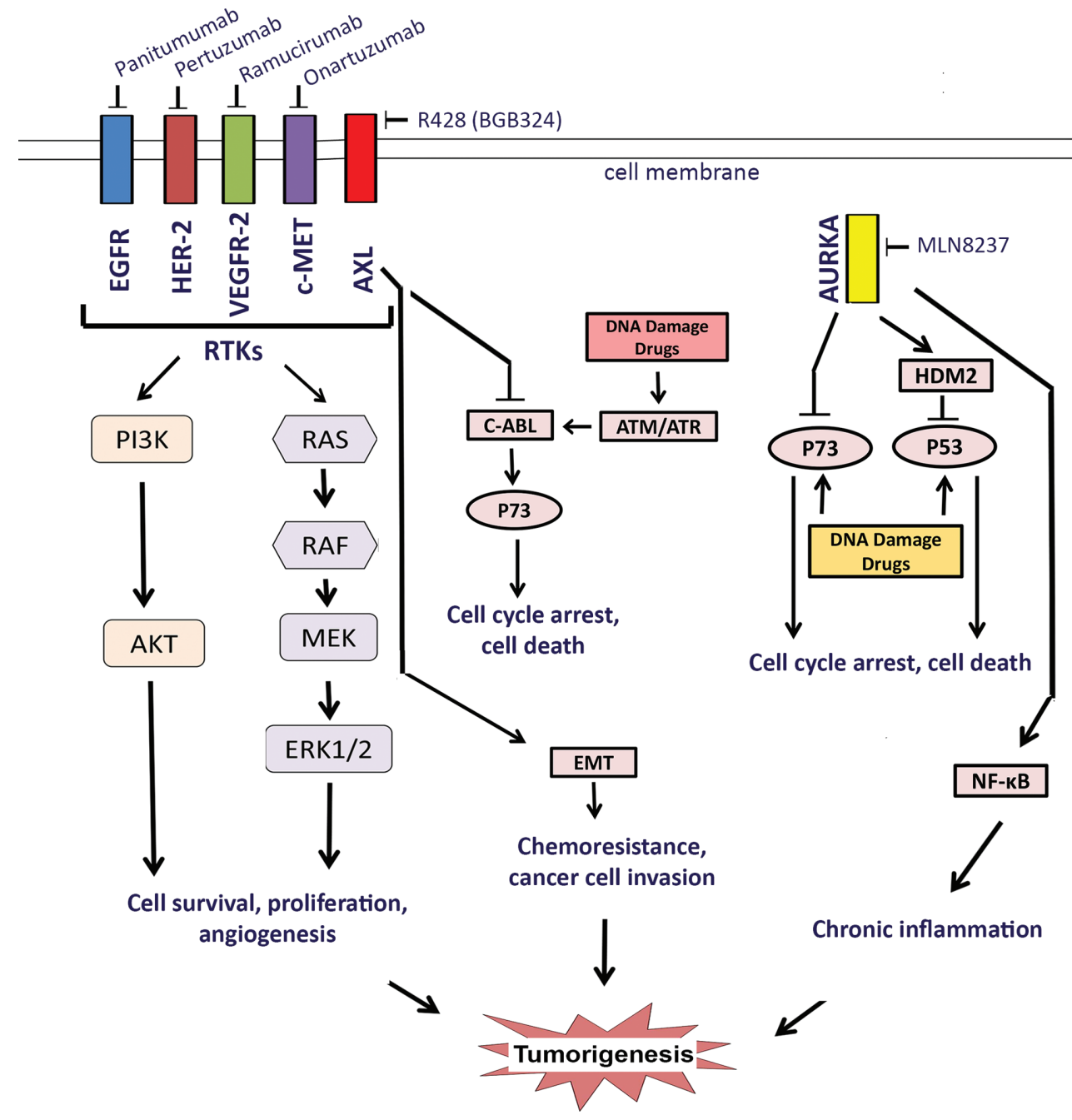

Figure 1: Constitutive activation of receptor and non-receptor protein kinases signaling promotes esophageal and gastro-esophageal tumorigenesis. Overexpression and/or gene amplification of RTKs, and to a lesser extent gain-of-function mutations of RTKs, lead to constitutive activation of down-stream signaling, resulting in uncontrolled cell growth, cell survival, angiogenesis, and ultimately tumorigenesis. Of note, AXL suppresses DNA damage-induced apoptosis through interaction and inhibition of c-ABL tyrosine kinase in esophageal AC [64]. In addition, AXL has been implicated in promoting epithelial-to-mesenchymal transition (EMT), cancer cell invasion, and drug resistance in many types of malignancies, including those of the breast [68, 90] and lung [72, 91]. Overexpression of AURKA, a serine/threonine kinase, attenuates DNA damage-induced cell cycle arrest and apoptosis through inhibition of p53 family members $[84,89]$. Furthermore, AURKA has been shown to activate NF- $\kappa$ B signaling, leading to chronic inflammation and gastric tumorigenesis [92]. Targeted monoclonal antibodies, panitumumab (EGFR), pertuzumab (HER-2), ramucirumab (VEGFR-2), and onartuzumab (c-MET), are currently being tested in combination with first-line chemotherapies in patients with gastric and gastroesophageal cancers (phase III clinical trials, Table 1). The AXL inhibitor, R428 (BGB324), AURKA inhibitor, MLN8237, have been investigated in esophageal AC, mostly in pre-clinical studies. However, a limited phase I/II clinical study has tested MLN8237 in patients with solid tumors including esophageal cancers (results not reported).

very minimal clinical activity in patients with esophageal SCC/AC and GEJ, suggesting that better patient selection and combination with chemotherapy regimens may enhance the clinical outcome [31]. In a phase II clinical trial, erlotinib (TKI) in combination with concurrent chemotherapy and radiotherapy in patients with advanced esophageal carcinomas has significantly improved the overall clinical response [32]. In a separate phase II study, erlotinib as a single agent in patients with unresectable or metastatic GEJ adenocarcinoma has shown some clinical benefits [33].

\section{Human epidermal growth factor receptor 2}

The human epidermal growth factor receptor 2 (HER-2), a member of the HER family, is a 185$\mathrm{kDa}$ transmembrane RTK without a known activating ligand [34]. HER-2 is activated through its dimerization with other members of the HER family including EGFR and HER-3 [35], leading to the subsequent activation of downstream signaling. The fact that HER-2 overexpression and amplification have been associated with poor prognosis in ovarian and breast cancers [36, 37], 
led to the development and approval of trastuzumab $\mathrm{mAb}$ to target HER-2 in breast tumors [38]. The initial success of trastuzumab targeted therapy in breast cancer led to its investigation in other types of HER2-overexpressing cancers. Overexpression of HER-2 in esophageal SCC (23\%) and GEJ (22\%) adenocarcinomas have been associated with poor response to neoadjuvant chemotherapy and overall poor survival, respectively [39]. In a Japanese clinical study, trastuzumab in combination with capecitabine/cisplatin or 5-fluorouracil/cisplatin in patients with advanced GEJ cancer improved overall survival as compared to chemotherapy alone [40]. In a randomized phase III study, pertuzumab $\mathrm{mAb}$, which is directed against HER-2, in combination with trastuzumab, 5-fluorouracil, capecitabine, and cisplatin is currently investigated in patients with HER-2-positive metastatic gastric or GEJ adenocarcinoma (NCT01774786). In addition, a randomized phase III clinical trial is currently ongoing to evaluate the efficacy and safety of trastuzumab emtansine (T-DM1) compared to standard taxane treatment in patients with HER-2-positive advanced or metastatic gastric or GEJ adenocarcinoma (NCT01641939). Lapatinib (TKI), a small-molecule inhibitor, which targets both EGFR and HER-2, was effective in patients with trastuzumab-resistant breast cancer [41]. In a phase II clinical study, lapatinib alone in patients with EGFRand/or HER-2-overexpressing esophageal AC showed very minimal clinical benefits [42]. In addition, a phase I clinical trial is currently ongoing to evaluate lapatinib in combination with paclitaxel in patients with GEJ adenocarcinoma (NCT00313599).

\section{Mesenchymal-epithelial transition factor}

The mesenchymal-epithelial transition factor (c-MET) RTK, consisting of alpha subunit (45 kDa) and beta subunit $(145 \mathrm{kDa})$, is activated by its ligand hepatocyte growth factor (HGF), leading to transduction of downstream signaling, including PI3K/AKT, mTOR, and STAT3 pathways [43]. Physiologically, c-MET promotes cell scattering and motility, which involves the disruption of cell-cell adhesion - a critical function in embryogenesis and wound healing [44]. The MET pathway has been chosen as a promising drug target because dysregulation of this pathway occurs in various types of human cancers, including human gastric and esophageal AC [45]. Several molecular mechanisms such as ligand/receptor overexpression or $c-M E T$ gene amplification can mediate such dysregulation. Notably, gene amplification of $c-M E T$ has been associated with poor prognosis in gastric and esophageal cancers [46]. The c-MET and its ligand HGF are potential therapeutic targets in upper gastrointestinal cancers. For instance, in a randomized global phase III study, onartuzumab mAb (MetMAb), which is directed against c-MET receptor, is currently investigated in combination with 5-fluorouracil, folinic acid, and oxaliplatin (mFOLFOX6) in patients with metastatic HER2-negative and MET-positive gastric and GEJ adenocarcinoma (NCT01662869). In addition, crizotinib, which is a small molecule inhibitor of c-MET - approved for the treatment of ALK-positive NSCLC by the FDA, has been shown to be effective in the treatment of a subset of patients with $c$-MET-amplified gastric or esophageal tumors [47]. Another c-MET TKI, tivantinib, is currently being tested in combination with chemotherapy (FOLFOX) in patients with GEJ and gastric adenocarcinoma (NCT01611857). The HGF mAb, rilotumumab, in combination with chemotherapy (ECX) has shown some survival benefit in patients with gastric and GEJ cancers, especially those expressing higher levels of c-MET [48]. Previous studies showed that acquired resistance to EGFR inhibitors was associated with gene amplification of $c-M E T$ in NSCLC [49], suggesting that combined targeting of EGFR and c-MET could be beneficial to overcome the onset of drug resistance.

\section{Vascular endothelial growth factor}

The vascular endothelial growth factor (VEGF), which belongs to the platelet-derived growth factor family, is the most potent proangiogenic factor that interacts with its receptors (VEGFR-1, -2, and -3). This will ultimately lead to vasculogenesis and angiogenesis [50]. Frequent overexpression of VEGF has been associated with increased microvessel density, tumor invasion and metastasis, and poor prognosis in many types of cancers [51]. VEGF is up-regulated in BE and esophageal AC, and overexpression of VEGF protein has been reported as a potential negative prognostic marker in esophageal SCC [51]. Therefore, VEGF may be a potential therapeutic target in esophageal cancers. In a phase III study, bevacizumab mAb, which binds to all isoforms of VEGF and hence prevent its binding to its receptors, in combination with chemotherapy (irinotecan) improved the overall response rate and survival of patients with colorectal carcinoma [52]. A phase II study revealed that bevacizumab in combination with irinotecan and cisplatin relatively enhanced the survival and clinical outcome of patients with metastatic gastric or GEJ adenocarcinoma [53]. Similarly, in a more recent phase II clinical trial, the combination of bevacizumab with docetaxel, cisplatin, and fluorouracil improved response rate and survival as compared to chemotherapy alone in patients with metastatic GEJ adenocarcinoma [54]. Ramucirumab, a fully humanized monoclonal antibody that binds to VEGFR2 and blocks angiogenesis, has been recently approved by the FDA as second-line therapy for patients with advanced gastric cancer or GEJ adenocarcinoma [55]. In a randomized phase III trial, ramucirumab monotherapy has improved survival in patients with advanced gastric or GEJ adenocarcinoma after first-line chemotherapy [56]. Several TKIs, which inhibit multiple RTKs including 
VEGF receptor, have been investigated. Sunitinib, as a single agent, has insufficient clinical value in patients with gastric or GEJ adenocarcinoma [57]. In addition, sunitinib is currently investigated in combination with chemotherapy (FOLFIRI) in patients with gastric and esophageal cancers (NCT00891878, NCT00524186). Another TKI, sorafenib, in combination with docetaxel and cisplatin improved the overall survival in patients with metastatic gastric or GEJ adenocarcinoma [58]. However, in a phase II study, sorafenib as a single agent is being investigated in patients with metastatic or recurrent esophageal SCC and AC, and GEJ adenocarcinoma (NCT00917462).

\section{AXL}

AXL, a receptor tyrosine kinase that belongs to the TAM subfamily (Tyro-3, AXL, and Mer), is a transmembrane protein that consists of extracellular two immunoglobin-like domains with two tandem fibronectin type III repeats, and a cytoplasmic kinase domain [59]. AXL binds to its ligand Gas-6 (growth arrest-specific gene 6) and activates downstream signaling, including

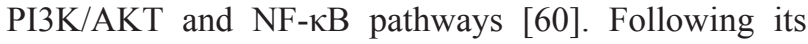
identification as a transforming gene in human chronic myelogenous leukemia [61], AXL has been shown to be overexpressed in several types of human cancers such as lung [62] and gastric [63] cancers. Of note, we [64], and others [65], have reported AXL overexpression in esophageal AC. In fact, AXL overexpression has been associated with tumor cell migration and invasion, epithelial-to-mesenchymal transition (EMT), and poor survival in different types of cancers [66, 67]. These studies highlight AXL as a promising target for cancer therapy. In this regard, Holland and colleagues [68] generated and characterized a highly selective smallmolecule inhibitor (R428, Rigel Pharmaceuticals) that potently blocks the catalytic activity of AXL and AXLdependent biological functions, including tumor cell invasion and angiogenesis in tumor mouse models. In a preclinical study, Li and colleagues [69] have developed AXL monoclonal antibodies that suppress NSCLC xenograft growth through downregulation of AXL expression and induction of apoptosis. Preclinical studies on AXL inhibitor TP-0903 (Tolero Pharmaceuticals \& Astex Pharmaceuticals) in pancreatic and lung cancers are ongoing [70]. BergenBio \& Rigel Pharmaceuticals have recently launched a clinical trial (phase I) to evaluate the AXL inhibitor BGB324 (formerly R428) in cancer patients [70]. In another phase I clinical study, a compound (S49076, Servier) that inhibits AXL/Mer and fibroblast growth factor receptors has been evaluated in patients with advanced solid tumors [70]. However, a new study urges caution as systemic inhibition of AXL and its closely related RTK, Mer, could promote colon cancers [71]. Of note, AXL and Mer are expressed in macrophages and dendritic cells mediating anti-inflammatory functions that prevent colon tumorigenesis [71]. Therefore, targeting AXL with the highly specific AXL inhibitors may be a less risky therapeutic approach than using other inhibitors with broad range specificity. The fact that AXL is frequently overexpressed and associated with poor prognosis in esophageal AC strongly suggests that AXL is an attractive therapeutic target in this human malignancy.

A recent interesting study demonstrated that activation of AXL kinase mediates resistance to EGFRtargeted therapy in lung cancer [72]. Another study showed that knockdown of AXL significantly improved in vitro response to standard chemotherapy by promoting apoptosis in NSCLC [73]. In this regard, we investigated the potential role of AXL in promoting resistance to standard chemotherapeutic agents in esophageal AC. Indeed, we demonstrated that AXL mediates resistance to the DNA-damaging drug (cisplatin) through regulation of c-ABL tyrosine kinase in p53-deficient esophageal AC cells. Mechanistic investigations showed that AXL attenuates cisplatin-induced apoptosis through blocking nuclear accumulation of c-ABL and phosphorylation of p73 in response to DNA damage (Figure 1) [64]. The findings from this study and others [65] strongly support an initiative to evaluate AXL as a therapeutic target in combination with DNA-damaging chemotherapeutic agents in esophageal AC in preclinical and clinical settings. This combination therapeutic approach may be valuable to overcome the frequent occurrence of drug resistance in patients with esophageal AC.

\section{Aurora kinase A}

Aurora kinase A (AURKA) — a member of a family that also includes aurora kinase $\mathrm{B}$ and $\mathrm{C}$ - is a serine/ threonine kinase, which is crucial for normal mitotic spindle formation and centrosome maturation and separation during cell division [74]. AURKA kinase activity is dependent on the phosphorylation of a threonine residue (T288) located on the activation loop of the kinase. We, and others, have previously reported the amplification of the region band 13, which harbors the $A U R K A$ gene, on the long arm of chromosome 20 (20q13) in upper gastrointestinal cancers $[75,76]$. In addition, the $A U R K A$ gene is frequently amplified and/or overexpressed in several types of cancer including those of the stomach [77] and esophagus [78]. Notably, AURKA overexpression has been significantly associated with more advanced stages of cancer and poor prognosis [79]. Pre-clinical studies showed that activation of AURKA leads to transformation of rodent fibroblast cells and the formation of multipolar mitotic spindles that induce genomic instability [80], establishing AURKA as a bona fide oncogene. AURKA blocks p53 tumor suppressor function through direct phosphorylation of p53 at Ser315, inducing MDM-2 mediated degradation of p53 protein [81]; and Ser215 to suppress its transcriptional activity in cancer cells [82]. Additionally, we uncovered that AURKA 
suppresses p53 through regulation of AKT-MDM-2 signaling in gastric cancer cells [83], and attenuates TAp73 transcriptional activity in p53 deficient cancer cells (Figure 1) [84]. We [83], and others [85], have reported that AURKA promotes survival of cancer cells through increased phosphorylation of AKT at Ser473. Because of their overexpression and association with tumorigenesis, aurora kinase family members have become the focus of drug discovery. Several aurora kinase small molecule inhibitors have been reviewed by Pollard and colleagues [86]. An increasing number of these inhibitors have been developed at preclinical or clinical stages. A secondgeneration investigational AURKA inhibitor (MLN8237/ alisertib, Millennium), which has 200-fold selectivity for AURKA over AURKB (aurora kinase B) in cell assays, has been recently investigated as monotherapy in phase I clinical trials in patients with advanced solid tumors or lymphomas (NCT01898078, NCT00962091). Notably, a phase I/II study on MLN8237 in patients with solid tumors including esophageal and gastric cancers has just been completed, yet the results have not been reported to date (NCT01045421). In preclinical studies, we investigated whether the combination of MLN8237 with standard chemotherapeutic agents could have a better therapeutic outcome in upper gastrointestinal cancers. Indeed, we found that MLN8237 in combination with cisplatin or docetaxel significantly enhanced cell death in esophageal AC xenograft mouse models [87, 88]. Mechanistic investigations indicated that AURKA promotes resistance to DNA damaging agents through activation of HDM2, a negative regulator of $\mathrm{p} 53$, thereby confirming that inhibition of AURKA in combination with chemotherapy is a good therapeutic approach in upper gastrointestinal cancers [89]. These results strongly support the initiation of clinical studies on MLN8237 in combination with standard chemotherapeutic agents in patients with upper gastrointestinal cancers. Additional preclinical studies on combinations of MLN8237 with targeted drugs (listed above) are required prior to designing clinical trials in patients with upper gastrointestinal cancers, especially those who have developed acquired resistance to first-line chemotherapy.

\section{Conclusions}

Esophageal cancer is characterized by resistance to current first-line therapies and dismal clinical outcome, underscoring the urgent need for more effective and innovative treatment strategies. Unlike other types of cancer, elucidation of the molecular mechanisms that regulate esophageal tumorigenesis of both histologic types has been incomplete. Our understanding of cancer biology coupled with the development of targeted drugs will have a positive impact in the treatment of esophageal cancer. The current ongoing clinical trials of targeted drugs in esophageal cancer patients have been mostly based on molecular targets identified in other malignancies. However, identification of AURKA and AXL as important players in esophageal tumorigenesis and drug resistance strongly justifies evaluating the available drugs targeting these molecules in clinical trials. As targeted therapy has been marred by drug resistance, it is imperative to preemptively identify the underlying molecular mechanisms and develop strategies to overcome them in a clinical setting. Notably, development of biomarkers of drug response and resistance may be useful in future clinical trials and rational management of cancer patients.

\section{Authors' contribution}

Abbes Belkhiri: Writing the manuscript and assembling figures

Wael El-Rifai: Writing the manuscript and finalizing the details

\section{Conflicts of interest}

The authors declare no potential conflicts of interest.

\section{REFERENCES}

1. Jemal A, Simard EP, Dorell C, Noone AM, Markowitz LE, Kohler B, Eheman C, Saraiya M, Bandi P, Saslow D, Cronin KA, Watson M, Schiffman M, Henley SJ, Schymura MJ, Anderson RN, et al. Annual Report to the Nation on the Status of Cancer, 1975-2009, featuring the burden and trends in human papillomavirus(HPV)-associated cancers and HPV vaccination coverage levels. Journal of the National Cancer Institute. 2013; 105:175-201.

2. Parkin DM, Bray F, Ferlay J, Pisani P. Estimating the world cancer burden: Globocan 2000. International Journal of Cancer. 2001; 94:153-156.

3. Thrift AP, Whiteman DC. The incidence of esophageal adenocarcinoma continues to rise: analysis of period and birth cohort effects on recent trends. Annals of oncology: official journal of the European Society for Medical Oncology/ESMO. 2012; 23:3155-3162.

4. Blot WJ, McLaughlin JK. The changing epidemiology of esophageal cancer. Seminars in oncology. 1999; 26:2-8.

5. Atabek U, Mohit-Tabatabai MA, Rush BF, Ohanian M, Rovelli P. Impact of esophageal screening in patients with head and neck cancer. The American surgeon. 1990; 56:289-292.

6. Bjorge T, Hakulinen T, Engeland A, Jellum E, Koskela P, Lehtinen M, Luostarinen T, Paavonen J, Sapp M, Schiller J, Thoresen S, Wang Z, Youngman L, Dillner J. A prospective, seroepidemiological study of the role of human papillomavirus in esophageal cancer in Norway. Cancer research. 1997; 57:3989-3992.

7. Pera M, Manterola C, Vidal O, Grande L. Epidemiology of esophageal adenocarcinoma. Journal of surgical oncology. 2005; 92:151-159. 
8. Reid BJ. Barrett's esophagus and esophageal adenocarcinoma. Gastroenterology clinics of North America. 1991; 20:817-834.

9. Homs MY, v d Gaast A, Siersema PD, Steyerberg EW, Kuipers EJ. Chemotherapy for metastatic carcinoma of the esophagus and gastro-esophageal junction. The Cochrane database of systematic reviews. 2006; CD004063.

10. Mauer AM, Kraut EH, Krauss SA, Ansari RH, Kasza K, Szeto L, Vokes EE. Phase II trial of oxaliplatin, leucovorin and fluorouracil in patients with advanced carcinoma of the esophagus. Annals of oncology: official journal of the European Society for Medical Oncology/ESMO. 2005; 16:1320-1325.

11. Ilson DH, Saltz L, Enzinger P, Huang Y, Kornblith A, Gollub M, O’Reilly E, Schwartz G, DeGroff J, Gonzalez G, Kelsen DP. Phase II trial of weekly irinotecan plus cisplatin in advanced esophageal cancer. Journal of clinical oncology: official journal of the American Society of Clinical Oncology. 1999; 17:3270-3275.

12. Enzinger PC, Mayer RJ. Esophageal cancer. The New England journal of medicine. 2003; 349:2241-2252.

13. Song Y, Li L, Ou Y, Gao Z, Li E, Li X, Zhang W, Wang J, Xu L, Zhou Y, Ma X, Liu L, Zhao Z, Huang X, Fan J, Dong L, et al. Identification of genomic alterations in oesophageal squamous cell cancer. Nature. 2014; 509:91-95.

14. Dulak AM, Stojanov P, Peng S, Lawrence MS, Fox C, Stewart C, Bandla S, Imamura Y, Schumacher SE, Shefler E, McKenna A, Carter SL, Cibulskis K, Sivachenko A, Saksena G, Voet D, et al. Exome and whole-genome sequencing of esophageal adenocarcinoma identifies recurrent driver events and mutational complexity. Nature genetics. 2013; 45:478-486.

15. Bennasroune A, Gardin A, Aunis D, Cremel G, Hubert P. Tyrosine kinase receptors as attractive targets of cancer therapy. Critical reviews in oncology/hematology. 2004; 50:23-38.

16. Pierotti MA, Negri T, Tamborini E, Perrone F, Pricl S, Pilotti S. Targeted therapies: the rare cancer paradigm. Molecular oncology. 2010; 4:19-37.

17. Ferguson KM. Structure-based view of epidermal growth factor receptor regulation. Annual review of biophysics. 2008; 37:353-373.

18. Franklin WA, Veve R, Hirsch FR, Helfrich BA, Bunn PA, Jr. Epidermal growth factor receptor family in lung cancer and premalignancy. Seminars in oncology. 2002; 29:3-14.

19. Amado RG, Wolf M, Peeters M, Van Cutsem E, Siena S, Freeman DJ, Juan T, Sikorski R, Suggs S, Radinsky R, Patterson SD, Chang DD. Wild-type KRAS is required for panitumumab efficacy in patients with metastatic colorectal cancer. Journal of clinical oncology: official journal of the American Society of Clinical Oncology. 2008; 26:1626-1634.

20. Karapetis CS, Khambata-Ford S, Jonker DJ, O'Callaghan CJ, Tu D, Tebbutt NC, Simes RJ, Chalchal H, Shapiro JD, Robitaille S, Price TJ, Shepherd L, Au HJ, Langer C,
Moore MJ, Zalcberg JR. K-ras mutations and benefit from cetuximab in advanced colorectal cancer. The New England journal of medicine. 2008; 359:1757-1765.

21. Guo M, Liu S, Lu F. Gefitinib-sensitizing mutations in esophageal carcinoma. The New England journal of medicine. 2006; 354:2193-2194.

22. Cronin J, McAdam E, Danikas A, Tselepis C, Griffiths P, Baxter J, Thomas L, Manson J, Jenkins G. Epidermal growth factor receptor (EGFR) is overexpressed in highgrade dysplasia and adenocarcinoma of the esophagus and may represent a biomarker of histological progression in Barrett's esophagus (BE). The American journal of gastroenterology. 2011; 106:46-56.

23. Patel D, Bassi R, Hooper A, Prewett M, Hicklin DJ, Kang X. Anti-epidermal growth factor receptor monoclonal antibody cetuximab inhibits EGFR/HER-2 heterodimerization and activation. International journal of oncology. 2009; 34:25-32.

24. Enzinger PC, Burtness B, Hollis Dm, Niedzwiecki D, Ilson D, Benson AB, Mayer RJ, Goldberg RM. CALGB 80403/ECOG 1206: a randomized phase II study of three standard chemotherapy regimens plus cetuximab in metastatic esophageal and GE junction cancer. Journal of Clinical Oncology, ASCO Annual Meeting Abstracts. 2010; 28:4006.

25. Lorenzen S, Schuster T, Porschen R, Al-Batran SE, Hofheinz R, Thuss-Patience P, Moehler M, Grabowski P, Arnold D, Greten T, Muller L, Rothling N, Peschel C, Langer R, Lordick F. Cetuximab plus cisplatin-5-fluorouracil versus cisplatin-5-fluorouracil alone in first-line metastatic squamous cell carcinoma of the esophagus: a randomized phase II study of the Arbeitsgemeinschaft Internistische Onkologie. Annals of oncology: official journal of the European Society for Medical Oncology/ ESMO. 2009; 20:1667-1673.

26. Chan JA, Blaszkowsky LS, Enzinger PC, Ryan DP, Abrams TA, Zhu AX, Temel JS, Schrag D, Bhargava P, Meyerhardt JA, Wolpin BM, Fidias P, Zheng H, Florio S, Regan E, Fuchs CS. A multicenter phase II trial of single-agent cetuximab in advanced esophageal and gastric adenocarcinoma. Annals of oncology: official journal of the European Society for Medical Oncology/ESMO. 2011; 22:1367-1373.

27. Lordick F, Kang YK, Chung HC, Salman P, Oh SC, Bodoky G, Kurteva G, Volovat C, Moiseyenko VM, Gorbunova V, Park JO, Sawaki A, Celik I, Gotte H, Melezinkova H, Moehler M, et al. Capecitabine and cisplatin with or without cetuximab for patients with previously untreated advanced gastric cancer (EXPAND): a randomised, open-label phase 3 trial. The lancet oncology. 2013; 14:490-499.

28. Ling Y, Chen J, Tao M, Chu X, Zhang X. A pilot study of nimotuzumab combined with cisplatin and 5-FU in patients with advanced esophageal squamous cell carcinoma. Journal of thoracic disease. 2012; 4:58-62.

29. Waddell T, Chau I, Cunningham D, Gonzalez D, Okines AF, Okines C, Wotherspoon A, Saffery C, Middleton G, Wadsley J, Ferry D, Mansoor W, Crosby T, Coxon F, Smith D, 
Waters J, et al. Epirubicin, oxaliplatin, and capecitabine with or without panitumumab for patients with previously untreated advanced oesophagogastric cancer (REAL3): a randomised, open-label phase 3 trial. The lancet oncology. 2013; 14:481-489.

30. Rodriguez CP, Adelstein DJ, Rice TW, Rybicki LA, Videtic GM, Saxton JP, Murthy SC, Mason DP, Ives DI. A phase II study of perioperative concurrent chemotherapy, gefitinib, and hyperfractionated radiation followed by maintenance gefitinib in locoregionally advanced esophagus and gastroesophageal junction cancer. Journal of thoracic oncology: official publication of the International Association for the Study of Lung Cancer. 2010; 5:229-235.

31. Adelstein DJ, Rodriguez CP, Rybicki LA, Ives DI, Rice TW. A phase II trial of gefitinib for recurrent or metastatic cancer of the esophagus or gastroesophageal junction. Investigational new drugs. 2012; 30:1684-1689.

32. Li G, Hu W, Wang J, Deng X, Zhang P, Zhang X, Xie C, $\mathrm{Wu}$ S. Phase II study of concurrent chemoradiation in combination with erlotinib for locally advanced esophageal carcinoma. International journal of radiation oncology, biology, physics. 2010; 78:1407-1412.

33. Dragovich T, McCoy S, Fenoglio-Preiser CM, Wang J, Benedetti JK, Baker AF, Hackett CB, Urba SG, Zaner KS, Blanke CD, Abbruzzese JL. Phase II trial of erlotinib in gastroesophageal junction and gastric adenocarcinomas: SWOG 0127. Journal of clinical oncology: official journal of the American Society of Clinical Oncology. 2006; 24:4922-4927.

34. King CR, Kraus MH, Aaronson SA. Amplification of a novel v-erbB-related gene in a human mammary carcinoma. Science. 1985; 229:974-976.

35. Olayioye MA. Update on HER-2 as a target for cancer therapy: intracellular signaling pathways of ErbB2/HER-2 and family members. Breast cancer research: BCR. 2001; 3:385-389.

36. Yokota J, Yamamoto T, Toyoshima K, Terada M, Sugimura T, Battifora H, Cline MJ. Amplification of c-erbB-2 oncogene in human adenocarcinomas in vivo. Lancet. 1986; 1:765-767.

37. Slamon DJ, Godolphin W, Jones LA, Holt JA, Wong SG, Keith DE, Levin WJ, Stuart SG, Udove J, Ullrich A, et al. Studies of the HER-2/neu proto-oncogene in human breast and ovarian cancer. Science. 1989; 244:707-712.

38. Baselga J, Tripathy D, Mendelsohn J, Baughman S, Benz CC, Dantis L, Sklarin NT, Seidman AD, Hudis CA, Moore J, Rosen PP, Twaddell T, Henderson IC, Norton L. Phase II study of weekly intravenous recombinant humanized anti-p185HER2 monoclonal antibody in patients with HER2/neu-overexpressing metastatic breast cancer. Journal of clinical oncology: official journal of the American Society of Clinical Oncology. 1996; 14:737-744.

39. Ross JS, McKenna BJ. The HER-2/neu oncogene in tumors of the gastrointestinal tract. Cancer investigation. 2001; 19:554-568.
40. Sawaki A, Ohashi Y, Omuro Y, Satoh T, Hamamoto Y, Boku N, Miyata Y, Takiuchi H, Yamaguchi K, Sasaki Y, Nishina T, Satoh A, Baba E, Tamura T, Abe T, Hatake K, et al. Efficacy of trastuzumab in Japanese patients with HER2-positive advanced gastric or gastroesophageal junction cancer: a subgroup analysis of the Trastuzumab for Gastric Cancer (ToGA) study. Gastric cancer: official journal of the International Gastric Cancer Association and the Japanese Gastric Cancer Association. 2012; 15:313-322.

41. Cameron D, Casey M, Press M, Lindquist D, Pienkowski T, Romieu CG, Chan S, Jagiello-Gruszfeld A, Kaufman B, Crown J, Chan A, Campone M, Viens P, Davidson N, Gorbounova V, Raats JI, et al. A phase III randomized comparison of lapatinib plus capecitabine versus capecitabine alone in women with advanced breast cancer that has progressed on trastuzumab: updated efficacy and biomarker analyses. Breast cancer research and treatment. 2008; 112:533-543.

42. Hecht JR, Urba S, Koehler M, Ellis C, Gagnon R, Kemner A, et al. Lapatinib monotherapy in recurrent upper gastrointestinal malignancy: phase II efficacy and biomarker analyses. Gastrointestinal Cancers Symposium. 2008; (Abstract 43).

43. Trusolino L, Bertotti A, Comoglio PM. MET signalling: principles and functions in development, organ regeneration and cancer. Nature reviews Molecular cell biology. 2010; 11:834-848.

44. Corso S, Comoglio PM, Giordano S. Cancer therapy: can the challenge be MET? Trends in molecular medicine. 2005; 11:284-292.

45. Miller CT, Lin L, Casper AM, Lim J, Thomas DG, Orringer MB, Chang AC, Chambers AF, Giordano TJ, Glover TW, Beer DG. Genomic amplification of MET with boundaries within fragile site FRA7G and upregulation of MET pathways in esophageal adenocarcinoma. Oncogene. 2006; 25:409-418.

46. Nakajima M, Sawada H, Yamada Y, Watanabe A, Tatsumi M, Yamashita J, Matsuda M, Sakaguchi T, Hirao T, Nakano H. The prognostic significance of amplification and overexpression of c-met and c-erb B-2 in human gastric carcinomas. Cancer. 1999; 85:1894-1902.

47. Lennerz JK, Kwak EL, Ackerman A, Michael M, Fox SB, Bergethon K, Lauwers GY, Christensen JG, Wilner KD, Haber DA, Salgia R, Bang YJ, Clark JW, Solomon BJ, Iafrate AJ. MET amplification identifies a small and aggressive subgroup of esophagogastric adenocarcinoma with evidence of responsiveness to crizotinib. Journal of clinical oncology: official journal of the American Society of Clinical Oncology. 2011; 29:4803-4810.

48. Iveson $\mathrm{T}$, Donehower RC, Davidenko I, Tjulandin S, Deptala A, Harrison M, Nirni S, Lakshmaiah K, Thomas A, Jiang Y, Zhu M, Tang R, Anderson A, Dubey S, Oliner KS, Loh E. Rilotumumab in combination with epirubicin, cisplatin, and capecitabine as first-line treatment for gastric or oesophagogastric junction adenocarcinoma: an openlabel, dose de-escalation phase $1 \mathrm{~b}$ study and a double-blind, 
randomised phase 2 study. The lancet oncology. 2014; 15:1007-1018.

49. Engelman JA, Zejnullahu K, Mitsudomi T, Song Y, Hyland C, Park JO, Lindeman N, Gale CM, Zhao X, Christensen J, Kosaka T, Holmes AJ, Rogers AM, Cappuzzo F, Mok T, Lee $\mathrm{C}$, et al. MET amplification leads to gefitinib resistance in lung cancer by activating ERBB3 signaling. Science. 2007; 316:1039-1043.

50. Hicklin DJ, Ellis LM. Role of the vascular endothelial growth factor pathway in tumor growth and angiogenesis. Journal of clinical oncology: official journal of the American Society of Clinical Oncology. 2005; 23:1011-1027.

51. Kleespies A, Guba M, Jauch KW, Bruns CJ. Vascular endothelial growth factor in esophageal cancer. Journal of surgical oncology. 2004; 87:95-104.

52. Hurwitz H, Fehrenbacher L, Novotny W, Cartwright T, Hainsworth J, Heim W, Berlin J, Baron A, Griffing S, Holmgren E, Ferrara N, Fyfe G, Rogers B, Ross R, Kabbinavar F. Bevacizumab plus irinotecan, fluorouracil, and leucovorin for metastatic colorectal cancer. The New England journal of medicine. 2004; 350:2335-2342.

53. Shah MA, Ramanathan RK, Ilson DH, Levnor A, D'Adamo D, O'Reilly E, Tse A, Trocola R, Schwartz L, Capanu M, Schwartz GK, Kelsen DP. Multicenter phase II study of irinotecan, cisplatin, and bevacizumab in patients with metastatic gastric or gastroesophageal junction adenocarcinoma. Journal of clinical oncology: official journal of the American Society of Clinical Oncology. 2006; 24:5201-5206.

54. Shah MA, Jhawer M, Ilson DH, Lefkowitz RA, Robinson E, Capanu M, Kelsen DP. Phase II study of modified docetaxel, cisplatin, and fluorouracil with bevacizumab in patients with metastatic gastroesophageal adenocarcinoma. Journal of clinical oncology: official journal of the American Society of Clinical Oncology. 2011; 29:868-874.

55. Ramucirumab approved for gastric cancer . Cancer discovery. $2014 ; 4: 752-753$.

56. Fuchs CS, Tomasek J, Yong CJ, Dumitru F, Passalacqua R, Goswami C, Safran H, dos Santos LV, Aprile G, Ferry DR, Melichar B, Tehfe M, Topuzov E, Zalcberg JR, Chau I, Campbell W, et al. Ramucirumab monotherapy for previously treated advanced gastric or gastro-oesophageal junction adenocarcinoma (REGARD): an international, randomised, multicentre, placebo-controlled, phase 3 trial. Lancet. 2014; 383:31-39.

57. Bang YJ, Kang YK, Kang WK, Boku N, Chung HC, Chen JS, Doi T, Sun Y, Shen L, Qin S, Ng WT, Tursi JM, Lechuga MJ, Lu DR, Ruiz-Garcia A, Sobrero A. Phase II study of sunitinib as second-line treatment for advanced gastric cancer. Investigational new drugs. 2011; 29:1449-1458.

58. Sun W, Powell M, O’Dwyer PJ, Catalano P, Ansari RH, Benson AB. Phase II study of sorafenib in combination with docetaxel and cisplatin in the treatment of metastatic or advanced gastric and gastroesophageal junction adenocarcinoma: ECOG 5203. Journal of clinical oncology: official journal of the American Society of Clinical Oncology. 2010; 28:2947-2951.

59. Lemke G. Biology of the TAM receptors. Cold Spring Harbor perspectives in biology. 2013; 5:a009076.

60. Verma A, Warner SL, Vankayalapati H, Bearss DJ, Sharma S. Targeting Axl and Mer kinases in cancer. Molecular cancer therapeutics. 2011; 10:1763-1773.

61. Neubauer A, O’Bryan JP, Fiebeler A, Schmidt C, Huhn D, Liu ET. Axl, a novel receptor tyrosine kinase isolated from chronic myelogenous leukemia. Seminars in hematology. 1993; 30:34.

62. Shieh YS, Lai CY, Kao YR, Shiah SG, Chu YW, Lee $\mathrm{HS}, \mathrm{Wu} \mathrm{CW}$. Expression of axl in lung adenocarcinoma and correlation with tumor progression. Neoplasia. 2005; 7:1058-1064.

63. Wu CW, Li AF, Chi CW, Lai CH, Huang CL, Lo SS, Lui WY, Lin WC. Clinical significance of AXL kinase family in gastric cancer. Anticancer research. 2002; 22:1071-1078.

64. Hong J, Peng D, Chen Z, Sehdev V, Belkhiri A. ABL regulation by AXL promotes cisplatin resistance in esophageal cancer. Cancer research. 2013; 73:331-340.

65. Hector A, Montgomery EA, Karikari C, Canto M, Dunbar KB, Wang JS, Feldmann G, Hong SM, Haffner MC, Meeker AK, Holland SJ, Yu J, Heckrodt TJ, Zhang J, Ding P, Goff D, et al. The Axl receptor tyrosine kinase is an adverse prognostic factor and a therapeutic target in esophageal adenocarcinoma. Cancer biology \& therapy. 2010; 10:1009-1018.

66. Gjerdrum C, Tiron C, Hoiby T, Stefansson I, Haugen H, Sandal T, Collett K, Li S, McCormack E, Gjertsen BT, Micklem DR, Akslen LA, Glackin C, Lorens JB. Axl is an essential epithelial-to-mesenchymal transition-induced regulator of breast cancer metastasis and patient survival. Proceedings of the National Academy of Sciences of the United States of America. 2010; 107:1124-1129.

67. Han J, Tian R, Yong B, Luo C, Tan P, Shen J, Peng T. Gas6/Axl mediates tumor cell apoptosis, migration and invasion and predicts the clinical outcome of osteosarcoma patients. Biochemical and biophysical research communications. 2013; 435:493-500.

68. Holland SJ, Pan A, Franci C, Hu Y, Chang B, Li W, Duan M, Torneros A, Yu J, Heckrodt TJ, Zhang J, Ding P, Apatira A, Chua J, Brandt R, Pine P, et al. R428, a selective small molecule inhibitor of Axl kinase, blocks tumor spread and prolongs survival in models of metastatic breast cancer. Cancer research. 2010; 70:1544-1554.

69. Li Y, Ye X, Tan C, Hongo JA, Zha J, Liu J, Kallop D, Ludlam MJ, Pei L. Axl as a potential therapeutic target in cancer: role of Axl in tumor growth, metastasis and angiogenesis. Oncogene. 2009; 28:3442-3455.

70. Sheridan C. First Axl inhibitor enters clinical trials. Nature biotechnology. 2013; 31:775-776.

71. Bosurgi L, Bernink JH, Delgado Cuevas V, Gagliani N, Joannas L, Schmid ET, Booth CJ, Ghosh S, Rothlin CV. 
Paradoxical role of the proto-oncogene Axl and Mer receptor tyrosine kinases in colon cancer. Proceedings of the National Academy of Sciences of the United States of America. 2013; 110:13091-13096.

72. Zhang Z, Lee JC, Lin L, Olivas V, Au V, LaFramboise T, Abdel-Rahman M, Wang X, Levine AD, Rho JK, Choi YJ, Choi CM, Kim SW, Jang SJ, Park YS, Kim WS, et al. Activation of the AXL kinase causes resistance to EGFRtargeted therapy in lung cancer. Nature genetics. 2012; 44:852-860.

73. Linger RM, Cohen RA, Cummings CT, Sather S, MigdallWilson J, Middleton DH, Lu X, Baron AE, Franklin WA, Merrick DT, Jedlicka P, DeRyckere D, Heasley LE, Graham DK. Mer or Axl receptor tyrosine kinase inhibition promotes apoptosis, blocks growth and enhances chemosensitivity of human non-small cell lung cancer. Oncogene. 2013; 32:3420-3431.

74. Barr AR, Gergely F. Aurora-A: the maker and breaker of spindle poles. Journal of cell science. 2007; 120:2987-2996.

75. Rygiel AM, Milano F, Ten Kate FJ, Schaap A, Wang KK, Peppelenbosch MP, Bergman JJ, Krishnadath KK. Gains and amplifications of c-myc, EGFR, and 20.q13 loci in the no dysplasia-dysplasia-adenocarcinoma sequence of Barrett's esophagus. Cancer epidemiology, biomarkers \& prevention: a publication of the American Association for Cancer Research, cosponsored by the American Society of Preventive Oncology. 2008; 17:1380-1385.

76. El-Rifai W, Sarlomo-Rikala M, Andersson LC, Knuutila S, Miettinen M. DNA sequence copy number changes in gastrointestinal stromal tumors: tumor progression and prognostic significance. Cancer research. 2000; 60:3899-3903.

77. Sakakura C, Hagiwara A, Yasuoka R, Fujita Y, Nakanishi M, Masuda K, Shimomura K, Nakamura Y, Inazawa J, Abe T, Yamagishi H. Tumour-amplified kinase BTAK is amplified and overexpressed in gastric cancers with possible involvement in aneuploid formation. British journal of cancer. 2001; 84:824-831.

78. Tong T, Zhong Y, Kong J, Dong L, Song Y, Fu M, Liu Z, Wang M, Guo L, Lu S, Wu M, Zhan Q. Overexpression of Aurora-A contributes to malignant development of human esophageal squamous cell carcinoma. Clinical cancer research: an official journal of the American Association for Cancer Research. 2004; 10:7304-7310.

79. Jeng YM, Peng SY, Lin CY, Hsu HC. Overexpression and amplification of Aurora-A in hepatocellular carcinoma. Clinical cancer research: an official journal of the American Association for Cancer Research. 2004; 10:2065-2071.

80. Zhou H, Kuang J, Zhong L, Kuo WL, Gray JW, Sahin A, Brinkley BR, Sen S. Tumour amplified kinase STK15/ BTAK induces centrosome amplification, aneuploidy and transformation. Nature genetics. 1998; 20:189-193.

81. Katayama H, Sasai K, Kawai H, Yuan ZM, Bondaruk J, Suzuki F, Fujii S, Arlinghaus RB, Czerniak BA,
Sen S. Phosphorylation by aurora kinase A induces Mdm2mediated destabilization and inhibition of p53. Nature genetics. 2004; 36:55-62.

82. Liu Q, Kaneko S, Yang L, Feldman RI, Nicosia SV, Chen J, Cheng JQ. Aurora-A abrogation of p53 DNA binding and transactivation activity by phosphorylation of serine 215. The Journal of biological chemistry. 2004; 279:52175-52182.

83. Dar AA, Zaika A, Piazuelo MB, Correa P, Koyama T, Belkhiri A, Washington K, Castells A, Pera M, El-Rifai W. Frequent overexpression of Aurora Kinase A in upper gastrointestinal adenocarcinomas correlates with potent antiapoptotic functions. Cancer. 2008; 112:1688-1698.

84. Dar AA, Belkhiri A, Ecsedy J, Zaika A, El-Rifai W. Aurora kinase A inhibition leads to p73-dependent apoptosis in p53-deficient cancer cells. Cancer research. 2008; 68:8998-9004.

85. Guan Z, Wang XR, Zhu XF, Huang XF, Xu J, Wang LH, Wan XB, Long ZJ, Liu JN, Feng GK, Huang W, Zeng YX, Chen FJ, Liu Q. Aurora-A, a negative prognostic marker, increases migration and decreases radiosensitivity in cancer cells. Cancer research. 2007; 67:10436-10444.

86. Pollard JR, Mortimore M. Discovery and development of aurora kinase inhibitors as anticancer agents. Journal of medicinal chemistry. 2009; 52:2629-2651.

87. Sehdev V, Katsha A, Ecsedy J, Zaika A, Belkhiri A, El-Rifai W. The combination of alisertib, an investigational Aurora kinase A inhibitor, and docetaxel promotes cell death and reduces tumor growth in preclinical cell models of upper gastrointestinal adenocarcinomas. Cancer. 2013; 119:904-914.

88. Sehdev V, Peng D, Soutto M, Washington MK, Revetta F, Ecsedy J, Zaika A, Rau TT, Schneider-Stock R, Belkhiri A, El-Rifai W. The aurora kinase A inhibitor MLN8237 enhances cisplatin-induced cell death in esophageal adenocarcinoma cells. Molecular cancer therapeutics. 2012; 11:763-774.

89. Sehdev V, Katsha A, Arras J, Peng D, Soutto M, Ecsedy J, Zaika A, Belkhiri A, El-Rifai W. HDM2 Regulation by AURKA Promotes Cell Survival in Gastric Cancer. Clinical cancer research: an official journal of the American Association for Cancer Research. 2014; 20:76-86.

90. Asiedu MK, Beauchamp-Perez FD, Ingle JN, Behrens MD, Radisky DC, Knutson KL. AXL induces epithelial-tomesenchymal transition and regulates the function of breast cancer stem cells. Oncogene. 2014; 33:1316-1324.

91. Neel DS, Bivona TG. Secrets of drug resistance in NSCLC exposed by new molecular definition of EMT. Clinical cancer research: an official journal of the American Association for Cancer Research. 2013; 19:3-5.

92. Katsha A, Soutto M, Sehdev V, Peng D, Washington MK, Piazuelo MB, Tantawy MN, Manning HC, Lu P, Shyr Y, Ecsedy J, Belkhiri A, El-Rifai W. Aurora kinase A promotes inflammation and tumorigenesis in mice and human gastric neoplasia. Gastroenterology. 2013; 145:1312-1322 e1311-1318. 